Research Article

\title{
Development and Validation of a Complexometric and Potentiometric Titration Method for the Quantitative Determination of Zinc Pyrithione in Shampoo
}

\author{
Greciel E. Egurrola $\left(\mathbb{D}\right.$, Angela P. Mazabel $\mathbb{D}^{D}$, and Johnbrynner García $(\mathbb{D}$ \\ Belcorp Research and Development, Tocancipá 251017, Colombia \\ Correspondence should be addressed to Johnbrynner García; johngarcia@belcorp.biz
}

Received 26 October 2020; Accepted 24 December 2020; Published 6 January 2021

Academic Editor: Alessandro Buccolieri

Copyright (c) 2021 Greciel E. Egurrola et al. This is an open access article distributed under the Creative Commons Attribution License, which permits unrestricted use, distribution, and reproduction in any medium, provided the original work is properly cited.

\begin{abstract}
Most of the pharmaceutical and cosmetic products used for the treatment of dandruff have zinc pyrithione as an active ingredient; therefore; quantifying this component becomes necessary. The purpose of this study was the validation of two simple and fast methodologies in the quantification of zinc pyrithione for shampoo quality control to guarantee consumer safety. The first method comprised a manual complexometric titration, and the second comprised a potentiometric titration performed with an automatic titrator, obtaining sensitivity values of $0.0534 \%$ and $0.0038 \%$, respectively, precision expressed in RSD $\%$ values below than $1 \%$, and accuracy in recovery percentage greater than $99 \%$. Additionally, both methods were robust when subjected to significant changes in working conditions (temperature and $\mathrm{pH}$ ) and were selective even in the presence of interferences and degradation products. Finally, the methodologies were adequate to ensure the quality of shampoo to ensure the safety of consumers.
\end{abstract}

\section{Introduction}

Zinc pyrithione $(\mathrm{ZnPT})$ is an organometallic compound with chemical formula $\mathrm{C}_{10} \mathrm{H}_{8} \mathrm{~N}_{2} \mathrm{O}_{2} \mathrm{~S}_{2} \mathrm{Zn}$ that has bactericidal and fungicidal activity. It is the antifungal agent most used in shampoos for control of dandruff due to its versatility. ZnPT was developed in the 1950s and first used as an antidandruff agent in 1961 even though the reason for dandruff was not exactly known at the time $[1,2]$. Some factors that can trigger dandruff are environmental factors, hormonal problems, and imbalance in the microbial biome present in the scalp. The most common factor is imbalance in the microbial biome due to the increase in microorganisms of the Malassezia genus whose metabolic cycle involves the degradation of fatty acids, generating irritation and hyperflorative activity of the epidermis [3-6].

The mechanism of action that ZnPT follows as an antifungal agent varies and will depend on the microorganism being studied $[7,8]$. ZnPT depolarizes the microorganism membrane, preventing the transport of nutrients and energy production $[9,10]$, and can also increase the amount of copper present in the cell, diminishing the functions of ironsulfur proteins $[11,12]$. In addition to antifungal properties to combat dandruff, $\mathrm{ZnPT}$ acts at the cellular level by being cytostatic, regulating the uncontrolled division of scalp cells, and is antiseborrheic due to the sulfur groups in the molecule $[13,14]$.

Dandruff is a common problem that affects more than $50 \%$ of the world population; thus, the number of products to combat dandruff such as shampoos, conditioners, and creams has increased [15]. The Food and Drug Administration (FDA) has registered $\mathrm{ZnPT}$ as an active ingredient for over-the-counter (OTC) drugs. Products with $\mathrm{ZnPT}$ are divided into two categories: rinse products, where the allowed content is among of $0.3-2.5 \%$, and nonrinse products, where the allowed content is among of $0.1-0.25 \%$ $[16,17]$. Therefore, ZnPT is a safe active ingredient with no adverse effects reported in humans, except when used for prolonged periods of time where it can cause sensitivity [18-20].

Many analytical techniques exist to determine $\mathrm{ZnPT}$ in cosmetic and pharmaceutical products such as atomic 
absorption spectroscopy, high-performance liquid chromatography (HPLC), and UV/Vis spectrophotometry. However, these analytical techniques have some drawbacks regarding costs, an elaborate sample preparation, and long analysis times due to the complexity of cosmetic products [21-23].

In this study, two methodologies using titrations (complexometric and potentiometric) were validated where the analysis times are much shorter and do not require sample preparation. Since these titrations are faster and cheaper compared to others, they become practical alternatives for routine analyses of high number of samples. Validation was performed following the United States Pharmacopeia (USP) and International Conference on Harmonisation (ICH) guidelines, evaluating the selectivity, linearity, accuracy, precision, and robustness of the methods mentioned above in shampoo samples [24-26].

\section{Materials and Methods}

2.1. Reagents and Samples. Secondary standard of zinc pyrithione (Sigma Aldrich), fuming hydrochloric acid (Merck, 37\%), ethylenediaminetetraacetic acid (EDTA) solution (Merck, $0.01 \mathrm{M}$ ), eriochrome black $T$ indicator (Merck), ammonia solution (Merck, 25\%), hydrogen peroxide solution (Merck, 30\%), potassium chloride (Merck, $>99.9 \%$ ), ammonium chloride (Merck, >99.8\%), and Iodine solution (Merck, 0.05 M). The selected samples were three shampoo formulas (S1, S2, and S3) that have zinc pyrithione as a component. Additionally, a placebo of the shampoos analysed was used.

2.2. Method. ZnPT determination in shampoo was performed using complexometric and potentiometric titrations. For the complexometric titration, $6.0 \mathrm{~g}$ of the sample were weighed and diluted in water $(50 \mathrm{~mL})$. Then, $2.5 \mathrm{~mL}$ of hydrochloric acid were added while heating and gently stirring for ten $\mathrm{min} .0 .5 \mathrm{~mL}$ of hydrogen peroxide was added, and the mixture was cooled simultaneously. $\mathrm{pH}$ was adjusted with an ammonia solution and $2.5 \mathrm{~mL}$ of buffer solution $(\mathrm{pH}=10)$. Finally, the sample was titrated with EDTA $(0.01 \mathrm{M})$ using eriochrome black $T$ as an indicator. The equivalence point occurred when the color of the solution changes from violet to blue.

For the potentiometric titration, $6.3 \mathrm{~g}$ of the sample was weighed and transferred to the cell of the automatic titrator (Mettler Toledo, T70) along with $50 \mathrm{~mL}$ of water and $10 \mathrm{~mL}$ of fuming hydrochloric acid. The resulting sample was titrated with an iodine solution $(0.05 \mathrm{M})$ where the final point of the titration was indicated by a platinum electrode (Mettler Toledo, DMI 140-SC). Constant stirring was ensured during the titration.

\subsection{Method Validation}

2.3.1. Selectivity. In order to establish method selectivity, the responses obtained for blank solvents, placebo, zinc pyrithione standard solution, and placebo enriched with zinc pyrithione were compared. Moreover, the sample was subjected to various stress conditions such as photolysis ( $3 \mathrm{~h}$, UV exposure), thermolysis ( $3 \mathrm{~h}$, heating), and the action of oxidizing agents $(1.0 \mathrm{~mL}$, hydrogen peroxide).

2.3.2. Linearity. Linearity of the system and method was evaluated at five concentration levels from 0.2 to $1.4 \mathrm{w} / \mathrm{w} \%$. These solutions were prepared percentage by weight in a beaker, mechanically shaken, and sonicated for ten min. System linearity was determined using water as the solvent for the preparation of standard solutions, and method linearity was evaluated using an additive placebo. The criteria evaluated for linearity were the intersection, the slope, and the determination coefficient.

2.3.3. Detection and Quantification Limit. LOD and LOQ values were determined using the linearity curve with the equations $\mathrm{LOD}=3.3 \sigma / S$ and $\mathrm{LOQ}=10 \sigma / S$, where $\sigma$ is the standard deviation of y-intercepts of regression lines and $S$ is the slope of the line [27]. In addition, the accuracy of the LOQ was obtained.

2.3.4. Precision. Precision was determined through various parameters such as method and system repeatability, intermediate precision, and reproducibility. The system repeatability was evaluated with three ZnPT standard solutions of different concentrations $(0.2 \%, 0.8 \%$, and $1.4 \%)$, and method repeatability was evaluated with three shampoo samples. Intermediate precision was evaluated with the results of two analysts in two different days and reproducibility with the results in two laboratories. Results were estimated by calculating the relative standard deviation (RSD\%) for each parameter.

2.3.5. Accuracy. Accuracy was determined with three standard solutions of different concentrations, $0.2,0.8$, and $1.4 \mathrm{w} / \mathrm{w} \%$, of $\mathrm{ZnPT}$, performing six trials per solution. Accuracy was reported as percent recovery and RSD\% which were calculated globally for all concentration levels.

2.3.6. Robustness. Method robustness was evaluated with the experimental design of Youden-Steiner for five variables. Variables used for the complexometric titration were $\mathrm{pH}$, sample weight, heating time, stirring time, and sample resting time. Variables used for the potentiometric titration were $\mathrm{HCl}$ volume, sample resting time, titrant addition rate, speed, and stirring time. Eight tests were performed in duplicate changing the conditions mentioned above.

\section{Results and Discussion}

3.1. Selectivity. The response obtained for solvent blank and placebo was the same, as well as for critical sample and enriched placebo, confirming that the components of the matrix did not interfere in the analysis. The shampoo sample under photolytic and thermolytic conditions did not produce reactions that could interfere with the $\mathrm{ZnPT}$ 


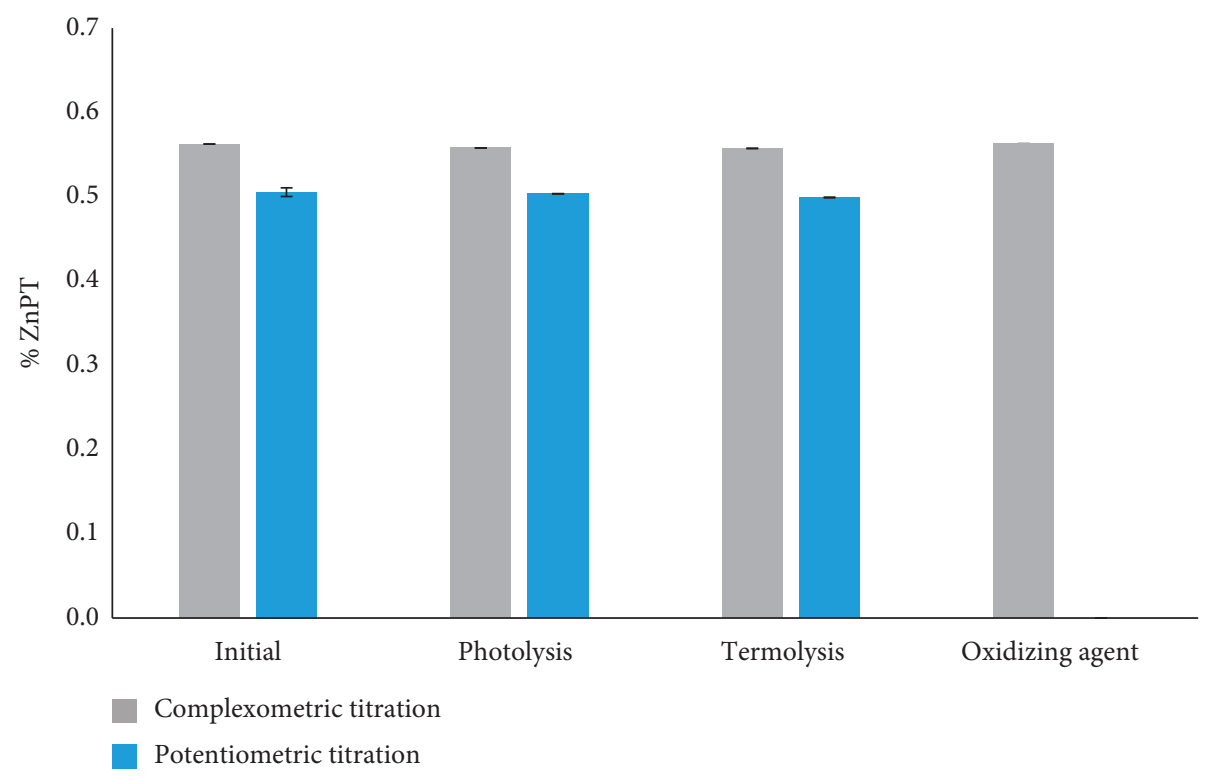

FIGURE 1: Selectivity of the method under stress conditions. The error bars represent the standard deviation of the replicates made for each working condition $(n=3)$.

measurement. However, under oxidative conditions, the analyte was not quantifiable for the potentiometric titration, as shown in Figure 1.

3.2. Linearity. Values of slope, intercept, and determination coefficient for the studied methods were calculated using the least squares method, and they are shown in Table 1 altogether with $\mathrm{t}$ values. Analysis of variance results (ANOVA) confirmed proportionality between the concentration and volume variables, since the F-calculate value is greater than $\mathrm{F}$ established in tables. In addition, Student's $t$-test results confirmed a significant linear correlation given that $\mathrm{t}$-calculate is greater than $t$ established in the table, which can be verified with the determination coefficient $(>0.99)$.

3.3. Sensitivity. LOD and LOQ values were calculated for the system and method of both titrations, obtaining data shown in Table 1, where values were lower for the potentiometric titration. LOQ accuracy was determined as percentage of recovery, generating values among $98 \%$ and $101 \%$ for the potentiometric and complexometric titrations, these values comply with the limits established for volumetric methods (95-105\%) [28]. Additionally, Student's $t$-test results confirmed that no significant difference was found between the recovery percentage values obtained and the theoretical 100\%; therefore, the LOQ was accurate in all cases.

3.4. Precision. Precision is generally expressed as the RSD\% of a series of measurements and expresses conformity or nonconformity regarding the proximity between multiple measurements under specific conditions [27]. RSD\% values for repeatability, reproducibility, and intermediate precision were less than $1.0 \%$ for the potentiometric and complexometric titration, as shown in Table 2 . The values of RSD\% were below the limit stipulated according to the Association of Official Analytical Chemists $(<5 \%)$ [28]; therefore, no significant difference was observed in results of multiple measurements, indicating that both methods are precise and reproducible.

3.5. Accuracy. The average recovery of the analytical methodologies was within the limits stipulated for volumetric methods (95-105\%) for the active ingredient, as shown in Table 2 . The $t$ calculated (0.44, complexometric titration and 0.14 , potentiometric titration) for the methodologies when compared to the $t$ in the table confirmed no statistically significant difference with the value of the average recovery obtained and $100 \%$ theoretical; thus, the methodologies were accurate.

3.6. Robustness. To determine the robustness of the method, the response obtained by slightly changing the experimental conditions of $\mathrm{pH}$, temperature, stirring time, standing time, and sample weight was evaluated. Effect of these variations was calculated for the two methodologies using the Youden-Steiner formulas and compared with the critical values of 0.0022 and 0.0038 for the potentiometric and complexometric titration $[29,30]$, as shown in Table 3. The critical value was calculated using equation $S * \sqrt{ } 2$, where $S$ is the standard deviation found in the repeatability of the methods. For the potentiometric titration, all values were less than the critical value; therefore, changes in conditions do not significantly affect the method response. For the complexometric titration, the change in the temperature and resting time conditions of the sample differed from the 
TABLE 1: Linearity and sensitivity of the methods studied.

\begin{tabular}{lcccc}
\hline \multirow{2}{*}{ Statistical parameters } & \multicolumn{2}{c}{ Method } & \multicolumn{2}{c}{ System } \\
& Potentiometric titration & Complexometric titration & Potentiometric titration & Complexometric titration \\
\hline Regression equation & $y=2.5202 x+0.0004$ & $y=18.899 x-0.0011$ & $y=2.5192 x-0.0003$ & $y=18.898 x-0.0035$ \\
Determination coefficient & 1 & 1 & 1 & 1 \\
Standard error of the slope & 0.0011 & 0.0049 & 0.0002 & 0.0032 \\
Standard intercept error & 0.001 & 0.0047 & 0.0002 & 0.0029 \\
$t$-calculate & 2349.9 & 3877.9 & 11330 & 5780.4 \\
Sensitivity (LOD) & 0.0013 & 0.0159 & 0.0004 & 0.0159 \\
Sensitivity (LOQ) & 0.0038 & 0.0534 & 0.0014 & 0.0534 \\
\hline
\end{tabular}

*\% ZnPT.

Table 2: Precision and accuracy $(n=6)$ of the method for potentiometric and complexometric titration.

\begin{tabular}{lccc}
\hline \multicolumn{1}{c}{ Parameter } & & Complexometric titration & Potentiometric titration \\
\hline Intermediate precision RSD\% & & 0.84 & 0.40 \\
Reproducibility RSD\% & $0.20 \%$ & 0.75 & 0.31 \\
& $0.80 \%$ & 0.02 & 0.25 \\
System repeatability RSD\% & $1.40 \%$ & 0.03 & 0.18 \\
& $\mathrm{~S} 1$ & 0.15 & 0.10 \\
Method repeatability RSD\% & $\mathrm{S} 2$ & 0.47 & 0.30 \\
& $\mathrm{~S} 3$ & 0.70 & 0.23 \\
Accuracy \% recovery & & 0.69 & 0.36 \\
Accuracy RSD \% & & 99.89 & 99.96 \\
\hline
\end{tabular}

TABle 3: Robustness of the method for potentiometric and complexometric titration.

\begin{tabular}{lcc}
\hline & Potentiometric titration & $\begin{array}{c}\text { Complexometric } \\
\text { titration }\end{array}$ \\
\hline Critical value & 0.0022 & 0.0038 \\
HCl volume & 0.0006 & $\mathrm{NR}^{*}$ \\
Heating temperature & $\mathrm{NR}^{*}$ & 0.0081 \\
$\mathrm{pH}$ & $\mathrm{NR}^{*}$ & 0.0027 \\
Rest time & 0.0016 & 0.0126 \\
Sample weight & $\mathrm{NR}$ & 0.0223 \\
Starring time & 0.0017 & 0.0018 \\
Starring velocity & 0.0014 & $\mathrm{NR}^{*}$ \\
Titrant addition rate & 0.0017 & $\mathrm{NR}^{*}$ \\
\hline *NR. no response & &
\end{tabular}

expected responses, suggesting that this methodology was less robust than the potentiometric titration.

\section{Conclusions}

Two simple and practical methods for the quantitative determination of $\mathrm{ZnPT}$ in cosmetic products were validated according to USP and ICH guidelines. Validated methods are specific, precise, exact, and linear in the range of concentrations studied. The sensitivity of both methods is adequate, allowing to confidently evaluate the $\mathrm{ZnPT}$ content in shampoo samples according to the concentrations established by the FDA. Furthermore, these two methodologies do not require complex sample preparation which makes them suitable techniques for the quality assurance of any shampoo to guarantee the consumer's well being.

\section{Data Availability}

The data used to support the findings of this study are available from the corresponding author upon request.

\section{Conflicts of Interest}

The authors declare that there are no conflicts of interest regarding the publication of this paper.

\section{Acknowledgments}

The authors wish to thank the innovation and development area of the company Belstar S. A for the concern shown and the financial support provided for the development and verification of analysis methodologies that allowed evaluating the quality and safety of products for consumer welfare.

\section{References}

[1] E. Guthery, L. A. Seal, and E. L. Anderson, "Zinc pyrithione in alcohol-based products for skin antisepsis: persistence of antimicrobial effects," American Journal of Infection Control, vol. 33, no. 1, pp. 15-22, 2005.

[2] R. M. Trüeb, "Shampoos: ingredients, efficacy and adverse effects,” JDDG, vol. 5, no. 5, pp. 356-365, 2007.

[3] R. J. Hay, "Malassezia, dandruff and seborrhoeic dermatitis: an overview," British Journal of Dermatology, vol. 165, pp. 2-8, 2011.

[4] J. R. Schawartz, Y. M. Deangelis, and T. L. Dawson, Chapter 12: Drandruff and Seborrheic Dermatitis: A Head Scratcher, pp. 389-414, Practical Modern Hair Science, Darmstadt, Germany, 2012. 
[5] G. A. Turner, M. Hoptroff, and C. R. Harding, "Stratum corneum dysfunction in dandruff," International Journal of Cosmetic Science, vol. 34, no. 4, pp. 298-306, 2012.

[6] G. Gaitanis, P. Magiatis, M. Hantschke, I. D. Bassukas, and A. Velegraki, "The Malassezia genus in skin and systemic diseases," Clinical Microbiology Reviews, vol. 25, no. 1, pp. 106-141, 2012.

[7] M. Park, Y. J. Cho, Y. W. Lee et al., "Understanding the mechanism of action of the anti-dandruff agent zinc pyrithione against Malassezia restricta," Scientific Reports, vol. 8, no. 1, 2018.

[8] D. Yasokawa, S. Murata, Y. Iwahashi et al., "DNA microarray analysis suggests that zinc pyrithione causes iron starvation to the yeast Saccharomyces cerevisiae," Journal of Bioscience and Bioengineering, vol. 109, no. 5, pp. 479-486, 2010.

[9] E. Ermolayeva and D. Sanders, "Mechanism of pyrithioneinduced membrane depolarization in Neurospora crassa," Applied and Environmental Microbiology, vol. 61, no. 9, pp. 3385-3390, 1995.

[10] C. J. Chandler and I. H. Segel, "Mechanism of the antimicrobial action of pyrithione: effects on membrane transport, ATP levels, and protein synthesis," Antimicrobial Agents and Chemotherapy, vol. 14, no. 1, pp. 60-68, 1978.

[11] N. L. Reeder, J. Xu, R. S. Youngquist, J. R. Schwartz, R. C. Rust, and C. W. Saunders, "The antifungal mechanism of action of zinc pyrithione," British Journal of Dermatology, vol. 165, pp. 9-12, 2011.

[12] N. L. Reeder, J. Kaplan, J. Xu et al., "Zinc pyrithione inhibits yeast growth through copper influx and inactivation of ironsulfur proteins," Antimicrobial Agents and Chemotherapy, vol. 55, no. 12, pp. 5753-5760, 2011.

[13] S. Leranoz, "La caspa. Causas Y Tratamiento," Offarm, vol. 21, no. 2, pp. 71-76, 2002.

[14] M. T. Alcalde and A. Pozo, "Principios activos anticaspa (I)," Offarm, vol. 25, no. 10, pp. 138-139, 2006.

[15] B. Sommer, D. Overy, and R. Kerr, "Identification and characterization of lipases from Malassezia restricta, a causative agent of dandruff," FEMS Yeast Research, vol. 15, no. 7, pp. 1-8, 2015.

[16] Dandruff, "seborrheic dermatitis and psoriasis drug products for over-the-counter human use: Amendment to the monograph,” Federal Register, vol. 59, pp. 4000-4001, 1994.

[17] Dandruff, "Seborrheic dermatitis, and psoriasis drug products containing coal tar and menthol for over-the-counter human use: amendment to the monograph, final rule," Federal Register, vol. 72, pp. 9849-9852, 2007.

[18] F. M. Williams, H. Rothe, G. Barrett et al., "Assessing the safety of cosmetic chemicals: consideration of a flux decision tree to predict dermally delivered systemic dose for comparison with oral TTC (Threshold of Toxicological Concern)," Regulatory Toxicology and Pharmacology, vol. 76, pp. 174-186, 2016.

[19] A. K. Rush, J. F. Nash, E. D. Smith III III, and G. B. Kasting, "Formulation and artificial sebum effects on the percutaneous absorption of zinc pyrithione through excised human skin," Skin Pharmacology and Physiology, vol. 32, no. 4, pp. 224-234, 2019.

[20] A. F. Nogueira, J. L. Pereira, S. C. Antunes, F. J. M. Gonçalves, and B. Nunes, "Effects of zinc pyrithione on biochemical parameters of the freshwater Asian clam Corbicula fluminea," Aquatic Toxicology, vol. 204, pp. 100-106, 2018.

[21] C. Y. Park, S. Moon, S. H. Baek et al., "Development of detection methods for zinc pyrithione in polypropylene via simple extraction methods for quality control," BioChip Journal, vol. 14, no. 2, pp. 211-217, 2020.

[22] S. Das and K. Khubdikar, "A simple and facile spectrophotometric tool for quantification of zinc pyrithione (ZPT) in suspension," Chemical Data Collections, vol. 19, pp. 1-6, 2019.

[23] A. Salvador, "Determination of selenium, zinc and cadmium in antidandruff shampoos by atomic spectrometry after microwave assisted sample digestion," Talanta, vol. 51, no. 6, pp. 1171-1177, 2000.

[24] FDA, "Analytical procedures and methods validation for drugs and biologics," Guide India, 2015.

[25] P. Borman and D. Elder, "Q2 (R1) validation of analytical procedures," in ICH Qual. Guidel. An Implement. Guid., A. Teasdale, D. Elder, and R. W. Nims, Eds., pp. 127-166, Wiley, Hoboken, NJ, USA, 1st edition, 2018.

[26] US Pharmacopeia 24, Validation of Compendial Methods, United States Pharmacopeal Convention, Records; Electronic Signatures, p. 2149, US Food and Rockville, Rockville, MD, USA, 1999.

[27] FDA, International Conference of Harmonization (ICH) Validation of Analytical Procedures: Text and Methodology, FDA, no. R1, Silver Spring, ML, USA, 2005.

[28] FDA, Guidelines for the Validation of Chemical Methods in Food, Feed, Cosmetics and Veterinary Products, FDA, Silver Spring, ML, USA, Third Edition, 2019.

[29] W. J. Youden and E. H. Steiner, "Statistical manual of the association of official analytical chemists," AOAC International, 1975.

[30] E. Karageorgou and V. Samanidou, "Youden test application in robustness assays during method validation," Journal of Chromatography A, vol. 1353, pp. 131-139, 2014. 